\title{
Projeto Eureka: A implantação da informática educativa na rede municipal de Campinas no período de 1989-1997
}

\author{
Karina Soledad Maldonado Molina Pagnez
}

\section{Resumo}

O problema de pesquisa deste estudo foi avaliar o processo de implantação de um projeto que pretendia introduzir o computador, na escola, como ferramenta pedagógica, portanto diretamente ligada à formação e ao trabalho do professor em sala de aula. $O$ projeto propôs uma formação de professores constituída por dois módulos: um intensivo e um extensivo, esta formação foi objeto central da avaliação realizada quanto à implantação do projeto. No que se refere à metodologia optamos por uma aná-

lise documental, dos planos de trabalho e atas de reunião de professores. Realizamos uma análise de conteúdo nas atas de reunião, definindo-se as categorias encontradas: troca de experiências, infra-estrutura, burocracia, cotidiano do professor, discussões pedagógicas e processo de formação .

Palavras-chave: Informática educativa. Projetos educacionais. Formação de professores.

\section{Abstract \\ Eureka Project: the implementation of educational computing in public schools of Campinas in the 1989-1997 period}

The objective of this study was to evaluate the implementation process of a computer introduction project in the school, as a pedagogical tool, therefore directly linked to the formation and the work of teachers in the classroom. The project has proposed the teachers formation in two modules: intensive and a extensive. This formation was the main objective of the evaluation carried through the implementation of the project. In what relates to the methodology we opt to a documentary analysis, of the work plans and the teachers meeting reports. We develop an analysis of the content of this meeting reports, defining the categories we have found: Exchange of 
experiences, infrastructure, bureaucracy, teachers daily activity, pedagogical quarrel and formation process.

Keywords: Educative computer science. Educational Projects and Teachers

Formation.

\section{Resumen}

\section{Proyecto Eureka: la} implantación de la informática educativa en la red municipal de campinas en el período de 1989 - 1997

El problema de pesquisa de este estudio fue avaliar el proceso de implantación de un proyecto que pretendia introduzir la computadora, en las escuelas, como herramienta pedagógica, por tanto directamente ligada a la formación y al trabajo del profesor en clases. El proyecto propone una formación de profesores constituída por dos módulos: un intensivo y un extensivo, esta formación fue objeto central de la avaliación realizada cuanto a la implantación del proyecto. En lo que se refiere a la metodologia optamos por una análisis documental, de los planos de trabajo y actas de reuniones de profesores. Realizamos una análisis del contenido de las actas de reuniones, definindo las categorias encontradas: intercambio de experiencias, infraestructura, burocracia, cotidiano del profesor, discusiones pedagógicas y proceso de formación.

Palabras clave: Informática educativa. Proyectos educacionales. Formación de profesores.

\section{Introdução}

A utilização do computador na educação tem sido objeto de muita discussão e pesquisa, nas últimas décadas. Este artigo descreve uma pesquisa que avaliou a implantação de um projeto educacional que tinha o objetivo de implantar o computador como ferramenta pedagógica, a partir da formação continuada em serviço do corpo docente.

Em 1989, o projeto foi inovador não apenas por introduzir o computador na prática pedagógica, a partir da formação, mas também por:

1) propor uma estrutura diferenciada, oferecendo cursos de formação e acompanhando a construção da nova prática dos professores, em sala de aula;

2) acreditar que seria possível transferir o know-how da academia para a rede municipal de ensino.

A avaliação proposta verificou, no discurso dos professores, como ocorreu o processo de implantação do projeto, que seria formado por dois módulos: um intensivo e outro extensivo. $\bigcirc$ módulo intensivo constituía-se de cursos com 40 horas de duração, ministrados anualmente para os professores interessados em dele participar (iniciação), ou para professores que já estavam trabalhando dentro da proposta (cursos de aprofundamento).

módulo extensivo consistia nos grupos de trabalho com reuniões semanais, realizadas em cada escola pelos professores que faziam parte do projeto, independentemente da classe ou série em que lecionavam. Uma outra parte integrante do módulo extensivo eram as reuniões de grupos de estudo, em encontros mensais com todos os professores de todas as escolas nele envolvidas, para o aprofundamento teórico e prático. 
Das reuniões semanais resultaram atas nas quais pudemos encontrar o discurso dos professores; este foi o meio encontrado para dar voz aos profissionais que participaram do projeto e tentar entender como se deu o processo nestes grupos. Para a avaliação do projeto contamos com as atas de reunião, os planos anuais definidos como discurso oficial e utilizamos também duas entrevistas: uma com a idealizadora e coordenadora do projeto e outra com um dos coordenadores.

\section{A avaliação de projetos educacionais}

Para a estruturação do trabalho, buscamos na literatura estudos referentes à avaliação de projetos educacionais e encontramos em Oliveira (1983, p. 1) uma contribuição. Esta autora adaptou um protocolo para a Avaliação de Projetos e Programas Educacionais, no qual enfatiza a importância da avaliação de projetos:

Numa época de mudanças aceleradas como a atual, em que as inovações se sucedem vertiginosamente, a avaliação impõe-se cada vez mais e ganha maior aceitação. Portanto, não é surpreendente que à avaliação tenham sido atribuídos diversos papéis, dentre os quais o de orientar ações sociais e de assegurar, aos legisladores e planejadores, bases mais sólidas para julgamento de suas ações, para verificação da adequação dos serviços prestados aos diferentes públicos, bem como para aplicação de recursos financeiros e humanos.

No que se refere à propriedade de subsídio para ações de legisladores e planejadores, pretendemos que este trabaIho possa auxiliar novos empreendimentos educacionais, como subsídio para tomada de decisões.
Encontramos nos trabalhos de Popham (1983, p. 20), mais especificamente em sua definição de avaliação somatória, uma contribuição para nosso trabalho, pois o objeto de nossa análise é um projeto já encerrado:

A avaliação somatória refere-se à estimativa dos méritos focalizados nos programas de ensino completos. O avaliador somatório coleta informações e julga os méritos de uma unidade de ensino completa de maneira que se possam tomar decisões relativas a se deve conservar ou adotar a unidade de ensino já encerrada.

A fim de avaliar ou atribuir algum julgamento de valor ao projeto faz-se necessário contextualizá-lo.

\section{O projeto de implantação da informática educativa}

Em 1989 iniciou-se o processo de estruturação do projeto que pretendia mudar a cultura da escola, introduzindo uma inovação: o computador na prática pedagógica. Através de convênio entre a Prefeitura Municipal, (representada pela Secretaria Municipal da Educação) e a Universidade Estadual de Campinas, (representada pelo Laboratório de Educação e Informática Aplicada da Faculdade de Educação).

O financiamento para efetivação do projeto partiu do Ministério da Ciência e Tecnologia (Programa RHAE/CNPq) e da Finep - Financiadora de Estudos e Projetos, além de parcerias com empresas.

Com o projeto estruturado, fez-se necessária a elaboração dos critérios para seleção das escolas participantes. Na época foi adotado o seguinte critério: escolas 
que oferecessem o ensino fundamental regular e Fumec - Fundação Municipal para Educação Comunitária, tornando-se critério para exclusão de uma escola a não existência de classes da Fumec.

Em seu desenvolvimento o projeto vivenciou duas fases: a primeira de 1990 ao início do ano de 1995, envolvendo o projeto piloto e a fase de implantação; a segunda de 1995 a 1997, definida na documentação do projeto como a fase de expansão em que a Prefeitura Municipal determinou que todas as escolas do município deviam participar do projeto. Passamos do trabalho com cinco escolas para trinta e nove escolas; a implantação do projeto deu-se a toque de caixa, sem o preparo apropriado dos formadores, coordenadores e muito menos professores.

\section{O projeto e a formação de professores}

$\bigcirc$ projeto envolveu a formação de professores que atuassem na rede regular e suplência do ensino fundamental. Desta forma, o projeto não se limitava ao uso do computador, mas propunha uma nova filosofia para o trabalho pedagógico, construindo uma instância efetiva de interdisciplinaridade e local propício para a construção do aprender a aprender, por parte do professor.

Demo (1993) coloca que o professor não é mero repassador do conhecimento; ele deve analisar e interpretar os conteúdos que serão ensinados aos alunos. Dessa forma o professor assume a posição de aprendiz, e tem o prazer de aprender para ensinar, possibilitando ao aluno também o aprender a aprender. Esse aspecto rompe com o antigo paradigma da relação professor-aluno, em que um "ensinava" e ao outro restava ser um depositário de informações, decoradas e copiadas em provas para comprovar a aprendizagem.

Seria natural na prática com o projeto, alterar a relação professor-conhecimentoaluno. Não se pretendia apenas introduzir o computador na escola, mas oferecer um espaço diferenciado para a construção de conhecimento e uma metodologia para introduzir e inovar a educação, através da formação dos professores de forma continuada e em serviço.

A formação pode estimular o desenvolvimento profissional dos professores, no quadro de uma autonomia contextualizada da profissão docente. Valorizando paradigmas de formação que promovam a preparação de professores reflexivos, que assumam a responsabilidade do seu próprio desenvolvimento profissional e que participem como protagonistas na implementação das políticas educativas.

Compreendemos a formação dos professores dessa forma, com o auxílio de Nóvoa (1992, p. 27), que salienta:

É preciso investir positivamente os saberes de que o professor é portador, trabalhando-os de um ponto de vista teórico e conceptual. Os problemas da prática profissional docente não são meramente instrumentais; todos eles comportam situações e problemáticas que obrigam a decisões num terreno de grande complexidade, incerteza e de conflitos de valores.

Aliada a esta necessidade de formação, temos a prática pedagógica à qual Kramer 
(1989, p. 190) atribui mais um aspecto: [...] compreensão da prática pedagógica como prática social e identificação do professor como ator vital nesse processo [...] os mecanismos de formação do professor (no caso, em serviço) devem ser percebidos como prática social inevitavelmente coerente com a prática que se pretende implantar na sala de aula entre professores e alunos.

Dentro deste panorama realizamos a pesquisa a seguir.

\section{Metodologia}

Neste trabalho foi definida a fase de 1990 a 1995 como corpus da análise documental. Acreditamos, como Lüdke e André (1986), que a análise documental busca identificar informações factuais nos documentos, a partir de questões ou hipóteses.

Desta forma os documentos constituem uma fonte estável e rica de informações;

- Possibilita diferentes análises, persistindo ao longo do tempo;

- Fonte natural de informação;

- Surgem em determinado contexto, fornecendo informações sobre esse mesmo contexto.

$\mathrm{Na}$ definição de nossas fontes de informações encontramos em Luna (1996, p. 53-54), a seguinte contribuição:

O documento, como fonte de informação, assume diferentes formas: literatura pertinente a um assunto, anuários estatísticos e censos, prontuários médicos, legislação, etc. Como ocorre em relação às demais fontes, as informa- ções obtidas em documentos podem ser diretas e indiretas. No caso particular de documentos, essa distinção costuma assumir a denominação de fontes primárias (diretas) ou secundárias (indiretas). As obras originais de um autor são consideradas como fontes primárias, enquanto as traduções e comentários sobre esse autor já são consideradas fontes secundárias [...]. De um modo geral, quanto mais "oficial" for um documento, mais primária será a fonte [...].

As fontes primárias trabalhadas nesta pesquisa possuem essa característica "oficial" citada por Luna (1996), pois são documentos produzidos sobre $\mathrm{o}$ projeto a fim de explicitar sua estrutura organizacional e documentar as ações dos grupos de trabatho das escolas'.

Optamos pela análise documental por ser o instrumento mais apropriado aos dados que tínhamos disponíveis: os planos de trabalho e as atas de reunião dos professores.

Concordamos com Lüdke e André (PHILIPS, 1974, p. 187 apud LÜDKE; ANDRÉ, 1986, p. 38), que deveria a análise documental ser mais utilizada na área de educação, por representar um instrumento valioso para extrair significados de um vasto material escrito normalmente encontrado nessa área:

Embora pouco explorada não só na área de educação como em outras áreas de ação social, a análise documental pode se constituir numa técnica valiosa de abordagem de dados qualitativos, seja complementando as informações obtidas por

1 Grupos de trabalhos: são os grupos formados nas escolas participantes do projeto que pretendiam oferecer a formação continuada em serviço aos professores. 
outras técnicas, seja desfilando aspectos novos de um tema ou problemas. São considerados documentos 'quaisquer materiais escritos que possam ser usados como fonte de informação sobre o comportamento humano'. Estes incluem desde leis e regulamentos, normas, pareceres, cartas, memorandos, diários pessoais e autobiografias, jornais, revistas, discursos, roteiros de programas de rádio e televisão até livros, estatísticas e arquivos escolares.

A análise de conteúdo é vista enquanto técnica de trabalho que atendia às necessidades da pesquisa e é compreendida na pesquisa como "uma técnica de pesquisa para fazer inferências válidas e replicáveis dos dados para o seu contexto" (KRIPPENDORFF, 1980, p. 21).

Segundo Krippendorff (1980), pode haver variações nas unidades de análise, tomandose como unidade a palavra, o parágrafo, a sentença ou o texto todo. Alguns analistas preferem a contagem de palavras ou expressões, enquanto outros - entre os quais nos incluímos - optam por fazer análises temáticas.

A necessidade de consenso entre os pesquisadores sobre o conteúdo do material analisado é outro ponto importante a se observar. Mas entendemos que a concordância só deva ocorrer para os aspectos mais óbvios da comunicação ou quando há pontos de vista culturais e sociopolíticos similares entre os pesquisadores-analistas, pois a diversidade de pontos de vista e de enfoques parece contribuir para aumentar o conhecimento sobre algo do que para limitá-lo. Segundo Lüdke e André (1986, p. 41): "A exigência de consenso parece, pois, muito mais uma exigência do formalismo analítico característico dos esquemas clássicos de pesquisa do que da necessidade do ato de conhecer."

As autoras levantam ainda a questão de que o consenso anteriormente definido como fundamental para a análise de conteúdo, não é necessário para esta análise com enfoque qualitativo. Portanto, neste trabalho definimos que a análise de conteúdo que realizamos teve como enfoque uma abordagem qualitativa.

Compreendemos a análise de conteúdo como uma técnica de investigação feita por meio de uma análise qualitativa do conteúdo manifesto nas comunicações, a partir do conhecimento formal e experiencial, tendo por finalidade a interpretação dessas comunicações e a elaboração de um levantamento temático que resultará na construção de categorias de análise para os dados coletados.

\section{Coleta e análise de dados}

Para a coleta de dados nas atas de reunião, foi necessário realizar três etapas de trabalho:

- leitura inicial de todo o material; este universo compreendia 3.332 atas escritas à mão sem arquivo digital;

- organização e acondicionamento de todas as atas;

- seleção e coleta de dados, levantamento de temas e construção das categorias de análise.

Realizadas a leitura e organização do material, verificamos a inviabilidade de análise de toda a amostra e a necessidade de um recorte. Elegemos as escolas da fase 
inicial do projeto (1990-1992), por acreditarmos que elas:

a) possuam um histórico mais completo, oferecendo-nos o maior número de atas e principalmente de dados para a análise; b) não estavam sob influência do efeito da novidade;

c) tinham mais profundamente alicerçada a estrutura proposta (módulos intensivo e extensivo);

d) teriam condições para uma implantação focada nos objetivos;

e) tinham maturidade para gerenciar o projeto a partir da filosofia de trabalho.

Optamos pela análise das quatro primeiras escolas a fazer parte do projeto. Assim sendo, o corpus de análise foi constituído por 683 atas de reunião.

As escolas foram denominadas como Escola A, Escola B, Escola C e Escola D. E esta relação obedece à ordem de integração das mesmas ao projeto.

Na análise das atas dos grupos de trabaIho, realizamos inicialmente a seleção de temas que consideramos as evidências para a apropriação do projeto por parte dos professores.

Destacamos os temas que se apresentaram com maior freqüência ${ }^{2}$ na amostra da pesquisa:

- Troca de experiências;

- Infra-estrutura;

- Burocracia;

- Remuneração;

- Produção dos professores;

- Discussões pedagógicas;

- Formação;

- Limitações; e

- Estrutura de apoio.
Dos temas acima relacionados, construímos categorias de análise. Ao analisar cada uma das categorias, trazemos as palavras dos professores como evidências, investindo-os, como coloca Demo (1997), de poder argumentativo, possibilitando-lhes assumir o lugar que lhes foi atribuído, desde o início de principais atores do projeto.

Portanto, neste estudo usamos o conceito de categoria como sendo um grupo com um conjunto de atributos ou características comuns, que tem o poder de explicitar uma grande quantidade de fenômenos presentes no processo de implantação do projeto.

Construímos, então, a partir dos temas, as seguintes categorias de análise dos dados.

- Troca de experiências;

- Infra-estrutura;

- Burocracia;

- Cotidiano do professor;

- Discussões pedagógicas; e

- Processo de formação.

A categoria Troca de Experiência recebeu destaque nas palavras dos professores, ocupando grande parte dos GT's sendo significativa para o trabalho dos professores. Essa categoria aparece em 580 das atas analisadas, ocupando um universo de $85 \%$ do total. Em nossa análise, essa categoria é compreendida com a contribuição de Nóvoa (1992). Ele afirma que é fundamental para a formação do professor trocar suas experiências com outros professores. Portanto, o projeto ofereceria um espaço para que os professores trocassem suas experiências.

Partimos de ansiedades e incertezas, queixas e insatisfações de diversas ordens, mas através de necessidades individuais que depois se verificava serem

${ }^{2}$ Freqüência de $80 \%$, ou maior, nas atas que compõem a amostra. 
do grupo. A partir destas necessidades construía-se a prática que resultava da cooperação, trabalho em conjunto, diálogo entre pessoas e entre pessoas e disciplinas, gerando novas formas de conhecimentos e construindo a prática do dia-a-dia. (Escola B)

Relato de professor sobre como estão sendo as aulas no LIED e a partir das dificuldades encontradas conversamos, trocamos idéias e buscamos soluções, fazendo algumas atividades no computador para que as crianças (alunos) possam desenvolvê-las na aula. (Escola C) $\bigcirc$ grupo tem que discutir contando as angústias e insatisfações, porque é muito importante a reflexão a partir destes sentimentos, além de estreitar os laços entre os próprios professores e também entre os professores e alunos. (Escola C)

A categoria Infra-Estrutura está presente em 650 das atas analisadas, ocupando, portanto, $95 \%$ do material analisado. Nela, encontram-se os comentários e dados presentes nas atas no que se refere às condições materiais para a implantação do projeto, desde salas para instalar os laboratórios, funcionamento dos computadores e periféricos até a limpeza e manutenção dos LIED's.

A infra-estrutura é definida nesta pesquisa como uma das evidências do módulo extensivo, pois age sobre a implantação do projeto na escola. Segundo Demo (1993), a inovação, como meio para a transformação da prática do professor, e conseqüentemente da cultura da escola, deve estar acessível a fim de que a tecnologia possa ser dominada e humanizada.

Com base no levantamento temático realizado, constatamos que a infra-estrutura surgiu de forma marcante em todas as escolas analisadas, pelo fato de apresentar deficiências que dificultavam o trabalho dos professores.

Limpeza dos computadores foi feita pelos professores no horário do GT, pois a escola não estava realizando a limpeza. (Escola A)

O grupo preocupou-se com a infra-estrutura decidindo comprar um miniaspirador para limpar as máquinas, iremos cotar persianas e quadro branco. (Escola B) As impressoras não puderam ser instaladas pois foram enviadas sem os cabos para conexão. Sem a descrição da impressora as professoras compraram cabos que não serviram. (Escola $B$ ) Falta tinta na impressora e pensamos em pedir a colaboração dos alunos para comprar. Irei falar sobre isso com os professores do segundo GT para decidirmos o que fazer. A proposta de pedir dinheiro aos alunos foi levada à direção que concordou com a proposta. (Escola C)

$\bigcirc$ processo de insatisfação deflagrou um questionamento e um repensar sobre o projeto e sobre os responsáveis pela manutenção: "Reavaliação do suporte técnico que tem emperrado muito o trabalho" (Escola A); "Discussão sobre a responsabilidade da SME junto à escola para a instalação e manutenção do LIED" (Escola C); "O conserto das tomadas do LIED será realizado pelo GT pois a escola não realizou o conserto" (Escola D); "Os professores estão muito insatisfeitos com o não atendimento pela IMA aos problemas relacionados ao computador. $\bigcirc$ que gerou uma discussão bem ampla sobre o programa, desde a sua concepção filosófica até a prática do dia-a-dia" (Escola A).

Nas Escolas A e C, a burocracia foi encontrada em $100 \%$ das atas, via controle de 
presença, com a descrição do horário de chegada dos professores e destaque para os atrasos. Questionamos se esse seria um dos objetivos do GT, pois não vemos esses dados como significativos para a qualidade políica do projeto. Verificamos na documentação que os professores assinavam uma folha de presença na secretaria da escola. Esse documento era enviado para a Prefeitura, para a efetivação do pagamento das horas.

A escola B apresenta uma frase significativa para nossa análise: "Duas professoras somente puderam participar como ouvintes, pois já participavam de outro projeto." Devido ao fato de se burocratizar a participação dos professores, restringindo o número de projetos de que eles poderiam participar, muitos alunos foram impossibilitados de freqüentar o LIED.

A categoria Cotidiano do Professor refere-se aos fatos decorrentes da prática do professor com o projeto, dentre os quais encontramos atividades desenvolvidas pelo professor; diferentes situações que dificultam o trabalho e que não se referem a condições materiais para a implantação do projeto, mas às atividades desenvolvidas pelos professores e às situações do dia-a-dia por eles vivenciado. $O$ cotidiano do professor foi encontrado em 581 atas, ocupando o total de $85 \%$ do material analisado.

É justamente nesse contexto que se dá a mudança na prática do professor em função do trabalho com a tecnologia e com a elaboração de uma metodologia de trabaIho. Esse processo também possibilita e favorece a mudança do próprio professor, que foi abordada, na troca de experiências. Naquela categoria, ocorre o repensar sobre a prática; nesta, ocorre a prática, que é por nós interpretada como o momento em que se constatam as mudanças de postura do professor.

As Discussões Pedagógicas ocuparam 547 das reuniões dos grupos de trabalho nas escolas, e estão representadas em $80 \%$ das atas analisadas.

Segundo Nóvoa (1992), a formação do professor não se constrói pela acumulação de cursos, conhecimentos ou técnicas, mas sim por meio de um trabalho de reflexividade crítica sobre as práticas e de (re)construção permanente de uma identidade pessoal. A reflexividade é por nós compreendida como os momentos em que os professores discutiam a respeito de temas ligados ao projeto (estruturação e execução) e à (re)construção do conhecimento em função da estruturação da metodologia de trabalho, resultando em mudança na prática pedagógica e do próprio professor.

Discussões sobre propostas novas para o próximo ano, como maior rigor em aplicação das regras pré-estabelecidas. Um novo cronograma com horários e divisões da sala do computador e participação dos professores nos GT's. Talvez até pedir que façam alguns planos (projetos para executar no computador), ensinar à tartaruga. (Escola B)

Há uma incoerência entre a proposta da Secretaria, que propõe sempre que o professor/educador esteja engajado e seja dedicado à educação, cujo centro é o aluno, mas cerceia e impede que este professor seja dedicado e engajado à proposta pedagógica da EU, por uma questão puramente financeira. Achamos que o Programa Eureka como um todo (todos os seus elementos) deva lutar para modificar isso, uma vez que 
todas as escolas passarão a ter esse problema. (Escola B)

$\bigcirc$ que exige obrigatoriedade não traz satisfação mínima e vai contra a filosofia do Logo. Temos que vivenciar os conceitos do ambiente Logo em nossa prática para ensiná-los aos alunos. (Escola C)

O processo de formação está representado em 590 das 683 atas que constituíram o corpus de análise, portanto presente num total de $86 \%$ do material analisado.

Na categoria processo de formação foram reunidos todos os relatos em que aparecem cursos de formação nos quais são feitos comentários e observações a seu respeito. Mapeamos, portanto, quando os professores depuravam ou adquiriam conhecimento e a forma como eles viam esse processo, se atendia ou não às suas necessidades.

\section{Considerações finais}

Constatamos, pela análise dos dados, que havia uma diferença fundamental na forma como o projeto tratava a formação e a ansiedade dos professores em relação à formação no uso da tecnologia. Os problemas gerados referentes à parte técnica e prática, foram impedimento para a efetividade do projeto, como formação continuada em serviço.

projeto pretendia implantar a tecnologia como ferramenta para o trabalho pedagógico, mas os professores sentiam a necessidade de dominar a ferramenta. Esse aspecto torna-se evidente:

O Programa deve oferecer noções básicas para aqueles que não têm, com base em um questionário de sondagem. (Escola A)
Os professores solicitam mais oficinas pois acreditam que não adquiriram os conhecimentos necessários durante as oficinas e, após a realização das mesmas, as dúvidas persistem. As oficinas poderiam ser sobre os mesmos problemas já vistos, porque não foram resolvidos. (Escola C)

Pretendia, também, oferecer o apoio técnico-prático por meio de um órgão da Prefeitura, fato que nunca se efetivou. Em muitas das reuniões os professores apenas discutiam como resolver problemas técnicos no laboratório e nas máquinas, situações para as quais não haviam recebido nenhuma formação.

Fundamentalmente, essa categoria expressa que os cursos de formação não atendiam às expectativas dos professores, comprometendo o trabalho no Laboratório de Informática Educativa ( LIED) nas escolas, devido à insegurança decorrente da falta de conhecimento.

Foi documentado nos planos de trabaIho que o projeto não pretendia formar especialistas em informática, mas sim formar profissionais capazes de utilizar o computador como ferramenta pedagógica, mas este objetivo não foi atingido.

As categorias Infra-estrutura e Burocracia demonstram os limitantes vivenciados pelo projeto, os quais determinaram o fim de uma proposta teórico-metodológica estruturada que no momento em que deveria passar para a prática deturpou-se e desestruturou-se.

Concluímos com este trabalho que a implantação de uma tecnologia ou de uma 
metodologia de trabalho, envolve fatores que devem estar claramente definidos e organizados como pré-requisitos, pois podem afetar, interferir e comprometer o funcionamento e implantação de projetos. Estes fatores compreendem a infra-estrutura, manutenção e a burocracia. Que podem engessar e imobilizar o trabalho dos professores e principalmente o desenvolvimento deste tipo de projeto.

No que se refere à produção de conhecimento, a estrutura proposta pelo projeto de intercâmbio entre a academia e a escola é fundamental e a transferência de know-how para a autogerência configurara como uma inovação que deverá inspirar projetos futuros.

Em função dos limitantes à formação do professor, que não eram de ordem conceitual, mas decorrentes das condições materiais e burocráticas, os professores perdiam muito tempo do grupo de trabalho, discutindo e tentando equacionar esse tipo de problema, perdendo a oportunidade de amadurecer conceitualmente o conhecimento e construir a metodologia de trabalho, que realmente constituiriam a formação continuada em serviço.

\section{Referências}

DEMO, P. Desafios modernos da educação. Rio de Janeiro: Vozes, 1993.

GOLDBERG, M. A. A.; SOUZA, C. P. (Org.). Avaliação de programas educacionais: vicissitudes, controvérsias e desafios. São Paulo: EPU, 1982.

KRAMER, S. Melhoria da qualidade do ensino: o desafio da formação de professores em serviço. Revista Brasileira de Estudos Pedagógicos, Brasília, DF, maio/ago. 1989.

KRIPPENDORFF, K. Content analysis. Beverly Hills: Sage, 1980.

LÜDKE, M.; ANDRÉ, M. E. D. Pesquisa em educação: abordagens qualitativas. São Paulo: EPU, 1986. (Temas Básicos de Educação e Ensino).

LUNA, S. V. Planejamento de pesquisa: uma introdução. São Paulo: Educ, 1996.

NÓVOA, A. Formação de professores e profissão docente. In: NÓVOA, A. (Org.).Os professores e a sua formação. Lisboa, PT: D. Quixote, 1992. p. 15-33.

OLIVEIRA, T. R.Padrões para avaliação, projetos e materiais educacionais: reorganização, validação e estabelecimento de níveis de importância para a realidade brasileira. 1983. Dissertação (Mestrado)-Universidade Federal do Rio de Janeiro, Rio de Janeiro, 1983.

PAPERT, S. A máquina das crianças: repensando a escola na era da informática. Tradução Sandra Costa. Porto Alegre: Artes Médicas, 1994. 
POPHAM, W. J. Avaliação educacional. Tradução Vânia Maria Moreira Rasche, Vera Maria Moreira Kude e Maria das Graças Feldens. Porto Alegre: Globo, 1983.

RIPPER, A. O preparo do professor para novas tecnologias. In: OLIVEIRA, V. B. (Org.). Informática em psicopedagogia. São Paulo: Senac, 1996.

Recebido em: 21/03/2005

Aceito para publicação em: 16/02/2006 